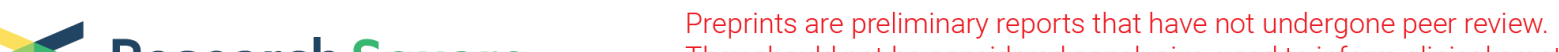 Research Square They should not be considered conclusive, used to inform clinical practice, or referenced by the media as validated information.
}

\section{Prognostic Factors in Conventional Chondrosarcoma Patients: a SEER Database Analysis}

\section{Peng Fu}

The Second Affiliated Hospital of Jiaxing University zhenzhen Gao

Jiaxing second hospital: The Second Affiliated Hospital of Jiaxing University

Ting Sun

The Second Affiliated Hospital of Jiaxing University

\section{Yi Bao}

The Second Affiliated Hospital of Jiaxing University

\section{Gang Chen ( $\square$ ludanbeko0907@163.com )}

The Second Affiliated Hospital of Jiaxing University https://orcid.org/0000-0001-5033-1770

\section{Research article}

Keywords: chondrosarcoma, Surveillance, Epidemiology, and End Results database, prognostic factor, nomogram, competing risk model

Posted Date: May 24th, 2021

DOI: https://doi.org/10.21203/rs.3.rs-517013/v1

License: (c) (i) This work is licensed under a Creative Commons Attribution 4.0 International License. Read Full License 


\section{Abstract}

Background: Conventional chondrosarcoma, a rare type of bone tumor, was resistant to chemotherapy and radiation therapy, so more characteristics were needed. In clinic, the use of small series and singleinstitution studies have limited the investigation of chondrosarcoma. The Surveillance, Epidemiologic, and End Results is the most complete and comprehensive database worldwide. Based on this database, the study aimed to collect clinicopathological features and detect the prognosis of patients with conventional chondrosarcoma.

Methods: Clinicopathologic and survival data of 782 patients from 2010 to 2016 and 353 patients from 2007 to 2009 were downloaded and analyzed. Overall survival was analyzed using the Kaplan-Meier method and verified by univariable Cox regression, and independent prognostic factors were assessed using the multi-variable Cox regression hazards model. Then, nomogram was established and the one-, three-, and five-year survival rates could be calculated with the nomogram. Competitive risk models were conducted to identify prognostic risk factors related to competitive endpoint events in patients with conventional chondrosarcoma.

Results: In total, 361 extremities, 360 axial bones, and 61 cranial samples were collected from the 2010 to 2016 cohort. The median survival time of patients with conventional chondrosarcoma was 35 months, and the independent prognostic factors were sex, grade, surgery, AJCC_M age, and tumor size. Thereafter, a nomogram was established based on those independent prognostic factors. The competitive risk model revealed no competitive risk for the cancer specific endpoint event. Those data from 2007 to 2009 were used to validate the results from 2010 to 2016 with general consistency. This retrospective study determined the prognostic factors in patients with conventional chondrosarcoma using the Cox regression hazards model. A nomogram was established to help oncologists assess this rare malignant tumor with low heterogeneity.

Conclusions: In the study, independent prognostic risk factors for conventional chondrosarcoma were identified, and a nomogram predicting three- and five- year overall survival rates were established, which may help physicians to predict the prognosis of patients with chondrosarcoma.

\section{Introduction}

Chondrosarcoma, which has an estimated incidence of $1: 200000^{[1]}$, is a type of malignant bone tumor characterized by the production of a cartilaginous matrix. Chondrosarcoma accounts for approximately $30 \%$ of all primary bone malignancies ${ }^{[2]}$, second only to osteosarcoma. Conventional chondrosarcoma constitutes approximately $85 \%$ of all chondrosarcoma cases, and the remaining subtypes include dedifferentiated $^{[3]}$, mesenchymal[ ${ }^{[4]}$, myxoid ${ }^{[5]}$, and clear cell chondrosarcoma ${ }^{[6]}$. The discrepant clinical outcomes of chondrosarcoma depend on histology, grade, and sex. Chondrosarcoma is resistant to chemotherapy and radiotherapy because of its extracellular matrix, low percentage of dividing cells, and poor vascularity ${ }^{[1,7]}$. The identification of IDH1/2 $2^{[8]}, \operatorname{COL} 2 \mathrm{~A}^{[9]}$, and $\mathrm{HIF} 2 \mathrm{a}^{[10]}$ in chondrosarcoma may be 
related to targeted agents, although the future role and effectiveness of which are dismal. Surgical excision remains the mainstay of treatment.

The Surveillance, Epidemiology, and End Results (SEER) database comprises approximately 30\% cancer survival data of the US population and is used to describe and analyze prognostic factors of malignant tumors worldwide ${ }^{[11]}$. The SEER database is important for rare diseases such as chondrosarcoma. Large multi-agency datasets allow the representation of disease statistics and population levels impossible to replicate outside of national databases. Some studies have collected raw data from the SEER database dating back to the 1970s despite the improvements in diagnosis and treatment with time, which may result in bias. In this study, we collected data on conventional chondrosarcoma from the SEER database from 2010 to 2016 as the test group and from 2007 to 2009 as the validation group. Thereafter, we identified prognostic factors using univariable and multivariable regression analyses and established a nomogram to predict the three- and five-year overall survival of chondrosarcoma.

\section{Materials And Methods}

This retrospective study utilized the SEER database to acquire cases in accordance with the Declaration of Helsinki (as revised in 2013). All data were collected from 18 local cancer registries, representing the total US population. SEER ${ }^{\star S t a t}{ }^{[12]}$ (version 8.3.5; National Cancer Institute, Bethesda, MD, USA) was used to acquire clinical data. The following information was collected in a unified form for each case: patient ID, sex, year of diagnosis, age at diagnosis, race, histology, stage, grade, type of surgery, cause of death, and COD (cause of death) to site recode. Samples of chondrosarcoma from 2010 to 2016 were collected as the test group and those from 2007 to 2009 were collected as the validation group.

ICD-0-3 ${ }^{[11,13]}$ (International Classification of Diseases for Oncology Third Edition) morphology codes were used to differentiate subtypes of conventional chondrosarcoma, excluding rare subtypes of nonconventional chondrosarcoma (mesenchymal [9240/3], myxoid [9231/3], clear cell [9242/3], dedifferentiated [9243/3], and juxtacortical [9221/3]). No information related to chemotherapy was found, whereas a small amount of information related to radiotherapy was found and collected. However, the radiotherapy plan was not given; thus, the variable radiotherapy was not added to the information table.

Patient identification was eliminated from the SEER database, therefore clinical studies using the SEER database do not require approval from the ethics board. All demographic data and tumor characteristics were identified using the $\chi^{2}$ test for correlations between categorical variables. Kaplan-Meier and Cox proportional hazard analyses were conducted to evaluate the prognostic value of gender, grade, primary site, AJCC_T(American Joint Committee on Cancer_T), AJCC_N, AJCC_M, tumor size, and surgery group for conventional chondrosarcoma.

Nomograms for one-, three-, and five-year overall survival (not cancer-specific survival) were established according to the previously mentioned results of multivariable Cox analysis. Then, the cmprsk $^{[11,14]}$ 
package in $\mathrm{R}$ was used to detect and visualize competing risk events. There may be more than one endpoint event for chondrosarcoma, and all other causes of death unrelated to the tumor are referred to as competing risk events. Patients died due to the tumor, the side effects of treatment, or cardiovascular disease. All statistical tests were performed at a level of significance of $p<0.05$.

\section{Results}

In this study, data were collected from the SEER database from which 782 conventional chondrosarcoma patients from 2010 to2016 categorized as the test group and 353 patients from 2007 to 2009 classified as the validation group. All the demographic data from both the test and validation groups are listed in Table 1. There was no significant difference in the distribution of data between the two groups. The mean age of the test group was $53.05 \pm 17.88$, and the mean age of the validation group was $50.31 \pm 17.94$. Sex was a significant factor, with male patients having worse prognosis than female patients $(p<0.05)$ (Table 1). Regarding histological grade, patients with undifferentiated grades had the shortest survival ( $H R=21.88, p<0.001)$. In addition, an increase in tumor stage (based on the AJCC system), age, and tumor size resulted in shortened survival for patients. Patients undergoing surgery had prolonged survival. Statistical tests were consistent between the test and validation groups, except for sex and surgery. 
Table 1

characteristics of conventional chondrosarcoma patients.

\begin{tabular}{|c|c|c|c|c|c|c|}
\hline & & 2010-2016 & & & 2007-2009 & \\
\hline Variables & $\begin{array}{l}\text { Total } \\
\text { number }\end{array}$ & $\mathrm{HR}(95 \% \mathrm{Cl})$ & $P$ & $\begin{array}{l}\text { Total } \\
\text { number }\end{array}$ & $\mathrm{HR}(95 \% \mathrm{Cl})$ & $P$ \\
\hline Gender & & & 0.01 & & & 0.22 \\
\hline Female & 345 & Ref & & 152 & Ref & \\
\hline Male & 437 & $\begin{array}{l}1.67(1.13- \\
2.47)\end{array}$ & & 201 & $\begin{array}{l}1.37(0.82- \\
2.27)\end{array}$ & \\
\hline Primary site & & & 0.10 & & & 0.46 \\
\hline Bones of Limbs & 361 & Ref & & 176 & Ref & \\
\hline Axial bones & 360 & $\begin{array}{l}1.04(0.72- \\
1.50)\end{array}$ & & 159 & $\begin{array}{l}0.79(0.48- \\
1.31)\end{array}$ & \\
\hline Bones of skull & 61 & $\begin{array}{l}0.23(0.05- \\
0.92)\end{array}$ & & 18 & $\begin{array}{l}0.52(0.13- \\
2.16)\end{array}$ & \\
\hline Grade & & & $<.001$ & & & $<.001$ \\
\hline Well-differentiated & 309 & Ref & & 143 & Ref & \\
\hline $\begin{array}{l}\text { Moderately } \\
\text { differentiated }\end{array}$ & 365 & $\begin{array}{l}2.32(1.23- \\
4.40)\end{array}$ & & 157 & $\begin{array}{l}2.66(1.12- \\
6.28)\end{array}$ & \\
\hline $\begin{array}{l}\text { Poorly- } \\
\text { differentiated }\end{array}$ & 88 & $\begin{array}{l}6.70(3.45- \\
13.00)\end{array}$ & & 37 & $\begin{array}{l}9.26(3.86- \\
22.19)\end{array}$ & \\
\hline undifferentiated & 20 & $\begin{array}{l}21.88(11.67- \\
41.05)\end{array}$ & & 16 & $\begin{array}{l}16.95(7.15- \\
40.15)\end{array}$ & \\
\hline AJCC_T & & & $<0.001$ & & & $\begin{array}{l}<.001 \\
0.001\end{array}$ \\
\hline T1 & 515 & Ref & & 235 & Ref & \\
\hline T2 & 261 & $\begin{array}{l}3.89(2.67- \\
5.72)\end{array}$ & & 115 & $\begin{array}{l}6.57(3.72- \\
11.59)\end{array}$ & \\
\hline T3 & 6 & $\begin{array}{l}3.93(0.95- \\
16.29)\end{array}$ & & 3 & $\begin{array}{l}\text { 13.81(3.17- } \\
60.219)\end{array}$ & \\
\hline AJCC_N & & & 0.01 & & & $\begin{array}{l}< \\
0.01\end{array}$ \\
\hline NO & 776 & Ref & & 351 & Ref & \\
\hline N1 & 6 & $\begin{array}{l}4.43(1.41- \\
13.97)\end{array}$ & & 2 & $\begin{array}{l}6.55(1.60- \\
26.86)\end{array}$ & \\
\hline
\end{tabular}




\begin{tabular}{|c|c|c|c|c|c|}
\hline & & 2010-2016 & & 2007-2009 & \\
\hline AJCC_M & & & $\begin{array}{l}<.001 \\
0.00\end{array}$ & & $\begin{array}{l}<.001 \\
0.001\end{array}$ \\
\hline MO & 757 & Ref & 341 & Ref & \\
\hline M1 & 25 & $\begin{array}{l}20.02(13.50- \\
29.69)\end{array}$ & 12 & $\begin{array}{l}11.37(6.14- \\
21.07)\end{array}$ & \\
\hline Tumor size(cm) & & & $\begin{array}{l}< \\
0.001\end{array}$ & & $\begin{array}{l}< \\
0.001\end{array}$ \\
\hline$<=8$ & 517 & Ref & 238 & Ref & \\
\hline$>8,<=13$ & 159 & $\begin{array}{l}3.11(1.98- \\
4.88)\end{array}$ & 74 & $\begin{array}{l}4.63(2.53- \\
8.50)\end{array}$ & \\
\hline$>13$ & 106 & $\begin{array}{l}5.31(3.41- \\
8.27)\end{array}$ & 41 & $\begin{array}{l}8.51(4.56- \\
15.90)\end{array}$ & \\
\hline Age & & & $\begin{array}{l}< \\
0.001\end{array}$ & & $\begin{array}{l}< \\
0.001\end{array}$ \\
\hline$<45$ & 272 & Ref & 129 & Ref & \\
\hline$>=45,<65$ & 369 & $\begin{array}{l}2.45(1.40- \\
4.29)\end{array}$ & 150 & $\begin{array}{l}2.19(1.12- \\
4.30)\end{array}$ & \\
\hline$>=65$ & 265 & $\begin{array}{l}3.56(2.02- \\
6.28)\end{array}$ & 74 & $\begin{array}{l}4.10(2.05- \\
8.22)\end{array}$ & \\
\hline Surgery & & & $<001$ & & 0.23 \\
\hline No sugery & 71 & Ref & 25 & Ref & \\
\hline Excision & 711 & $\begin{array}{l}0.20(0.13- \\
0.30)\end{array}$ & 328 & $\begin{array}{l}0.57(0.23- \\
2.27)\end{array}$ & \\
\hline
\end{tabular}

\section{Kaplan-Meier analysis and Cox regression model establishment}

Kaplan-Meier and log-rank tests were used to compare the differences between variables (Table 1). Factors that had a better outcome included: tumors with a lower histological grade, smaller tumor size, female sex, and a history of surgery (Fig. 1, Figure S1). Patients with an undifferentiated pathologic grade had the worst survival rate. In this study, a history of radiotherapy was included in the "type of resource" term, but we failed to segregate the variable due to the small sample size of patients undergoing radiotherapy. No differences were observed with respect to primary site. 
Based on the a-forementioned results of the univariable analysis, a multivariable Cox regression model was established to find the independent factors associated with long-term survival. A forest map was then established (Fig. 2). Sex, tumor size, surgery history, distant metastasis, grade, and age were independent prognostic factors for conventional chondrosarcoma patients. All the above results were consistent in the validation group. In the validation test, age and sex were heterogeneous factors (Figure S2). Therefore, we searched the "PubMed" database for confirmation, and we found a study that detected that females under 50 years old had a better outcome than those older than 50.

\section{Nomogram prediction establishment}

The significant prognostic factors generated from the multivariable Cox regression model were matched to establish the nomogram for one-, three-, and five-year overall survival (Fig. 3). In the nomogram, every variable had a scale value, and the sum of the scores predicted the survival rate. Thereafter, internal validation was performed using the bootstrapping method (parameter: $m=40, b=1000$ ), and the c-index was 0.85 (Fig. 4).

\section{Competing risk model analysis}

In this retrospective study, there were causes of death other than conventional chondrosarcoma. All the above analyses were related to overall survival, rather than cancer-specific survival; therefore, we conducted a competing risk analysis to differentiate the endpoint events (cancer-specific and non-cancerrelated death, and death from other causes). In total, 52 patients died from other causes of death including infection, heart disease, and chronic obstructive pulmonary disease. The model (Fig. 5, TableS1) indicated that the other causes of death had minor effects on the survival of patients with conventional chondrosarcoma.

\section{Discussion}

The incidence of chondrosarcoma is increasing: van Praag et al reported that the incidence of chondrosarcoma was 8.78 per million people between 2005 and 2013 in Netherland ${ }^{[15]}$, which is three times higher than that in the 1990s, and similar data exists for Norway ${ }^{[16]}$. The most common primary sites of chondrosarcoma are the bones of the limbs and associated joints, pelvic bones, ribs, clavicles, and the vertebral column ${ }^{[15,17]}$. To date, histological grade may still be the most important factor related to the prognosis of chondrosarcoma. Patients with grade II/III/IV disease have a significantly worse prognosis than those with grade I. There are four main pathological forms of chondrosarcoma: conventional, myxoid, juxtacortical, and dedifferentiated ${ }^{[18-20]}$. In our study, 20 patients $(2.6 \%)$ were diagnosed with a dedifferentiated morphology, which was reported to have a high distant metastasis rate. Nie et al ${ }^{[21]}$ demonstrated that the prognosis of chondrosarcoma was improved when comparing outcomes by decade based on the SEER database. However, chemotherapy and radiotherapy are not the mainstay therapies for chondrosarcoma. The primary goal is to better understand the characteristics of conventional chondrosarcomas since Amer et al ${ }^{[13,22]}$ reviewed and described non-conventional chondrosarcomas. In the present study, we identified prognostic factors of chondrosarcoma based on 
data from the SEER database from 2010 to 2016, which was verified using data from 2007 to 2009. Then, we established a nomogram to predict the overall survival of chondrosarcoma patients.

We found that females had a better prognosis in the univariable and multivariable analyses. The effect of sex on the prognosis of conventional chondrosarcomas is controversial. Several studies ${ }^{[9,20,23,24]}$ have reported sex as an independent risk factor based on the SEER database; however, sex did not influence survival in other studies ${ }^{[25-27]}$. Notably, Laitinen et al $^{[19]}$ found that females of hormone active age with chondrosarcoma had an improved overall survival, and survival was not carried forward in elderly patients. This was consistent with previous studies demonstrating that the estrogen receptor $\beta$ (ER $\beta)$ can be found in bone and endometrial sarcoma. Patients expressing hormone receptors had favorable outcomes $^{[11,28,29]}$. Further studies are necessary to elucidate the mechanism of sex hormones and chondrosarcoma.

Multivariable analysis showed that age, grade, AJCC_M, tumor size, sex, and surgery were independent risk factors for overall survival of patients with conventional chondrosarcoma, which was in line with previous studies. Surgery remains the optimal treatment for conventional chondrosarcoma and is associated with better outcomes than other treatments. However, the type of surgery for low-grade chondrosarcomas remains controversial. Donati ${ }^{[30]}$ suggested intralesional curettage in grade 1 pelvic chondrosarcoma to reduce operative morbidity, and Verdegaal ${ }^{[31]}$ (2012) reported that the use of phenol as an adjuvant after intralesional curettage of low-grade chondrosarcoma of a long bone had a good prognosis. However, Bus ${ }^{[25]}$ found that wide resection margins were associated with better outcomes compared to intralesional curettage in conventional chondrosarcoma of the pelvis. Hodel found that a wide resection was associated with a better prognosis than an unplanned intralesional resection, and the presence of an anatomical barrier was more important than the metric distance of the surgical margin. Stevenson ${ }^{[19]}$ reported that local recurrence in patients treated with intralesional curettage was high, which had a significant effect on survival, and suggested a 4-mm margin in all grades of chondrosarcoma because inadequate margins were associated with a high local recurrence rate. Therefore, we recommend that wide resection should be performed for all grades of chondrosarcoma.

We then established a nomogram based on the multivariable regression model from the 2010 to 2016 cohort. From the dispersion of the nomogram, distant metastasis other than in the lung, histological grade, and surgery were the most significant prognostic factors related to overall survival. The C-index calculated by bootstrap was 0.85 , confirming the reliability of our nomogram, and we expect it to be useful for clinicians and patients in the prognosis of conventional chondrosarcoma. Finally, we established a competing risk model to compare the competing risks of other death events reported in previous studies. The model showed that there were no competing risks regarding the endpoint events. However, we would like to clarify the discrepancy between the 2007-2009 and 2010-2016 cohorts. In the univariable analysis of the 2007-2009 cohort, sex and surgery were not significant prognostic factors for survival. There are some possible reasons for this: first, the surgical procedure was not as advanced as later years; second, the average age and the proportion of males and females in the 2007-2009 and 
2010-2016 cohorts were different, which may have caused a bias in the results of the 2007-2009 cohort.

Several limitations should be considered in the present study. First, we did not include variables such as specific tumor location, radiotherapy, and chemotherapy, which were associated with prognosis. Second, the SEER database does not provide information on local recurrence or marginal status. Third, the category of histological grade from the SEER database was different from the World Health Organization classification, which may be inaccurate. Finally, this was a retrospective study, which may have introduced bias.

In conclusion, we identified risk factors for overall survival of conventional chondrosarcoma based on the SEER database in the modern era, and established a nomogram to predict three- and five-year overall survival rates. New advances in the treatment of chondrosarcoma are expected, especially for patients with unresectable and metastatic diseases.

\section{Abbreviations}

SEER, Surveillance, Epidemiology, and End Results; ICD-0-3, International Classification of Diseases for Oncology Third Edition; American Joint Committee on Cancer, AJCC_T.

\section{Declarations}

\section{Ethics approval and consent to participate}

All data were downloaded from online database, thus no ethical approval and patient consent are required.

\section{Availability of data and materials}

All the data used in this study can be acquired from the online SEER database.

\section{Competing interests}

The author(s) declared no potential conflicts of interest with respect to the research, authorship, and/or publication of this article.

\section{Authors' contributions}

Z. Gao was responsible for the design. G. Chen and Y. Bao provided the administrative support. P. Fu and T. Sun were for the collection and assembly of data. P. Fu and Z. Gao were responsible for manuscript writing. All the authors approved the final manuscript.

\section{Acknowledgments}


None.

\section{Funding}

The author(s) disclosed receipt of the following financial support for the research, authorship, and/or publication of this article: Financial support was provided by Jiaxing Science and Technology Bureau(2018AD32008,2020AD30084) and Medical and health Science and Technology Project of Zhejiang Province (2021KY354).

\section{References}

1. Monga V, Mani H, Hirbe A, Milhem M: Non-Conventional Treatments for Conventional Chondrosarcoma. Cancers 2020, 12.

2. Yang Z, Niu N, Tang J, Wu L, He J, Shi J: Reconstruction of forearm support with ulnar translocation after resection of chondrosarcoma in the proximal radius. Der Orthopade 2020, 49:1006-12.

3. Wu S, Li P, Cai X, Hong Z, Yu Z, Zhang Q et al: Carbon Ion Radiotherapy for Patients with Extracranial Chordoma or Chondrosarcoma - Initial Experience from Shanghai Proton and Heavy lon Center. J Cancer 2019, 10:3315-22.

4. Boehme KA, Schleicher SB, Traub F, Rolauffs B: Chondrosarcoma: A Rare Misfortune in Aging Human Cartilage? The Role of Stem and Progenitor Cells in Proliferation, Malignant Degeneration and Therapeutic Resistance. Int J Mol Sci 2018, 19.

5. Flaman AN, Wasserman JK, Gravel DH, Purgina BM: Soft Tissue Special Issue: Chondroid Neoplasms of the Skull. Head and neck pathology 2020, 14:83-96.

6. Nagmani S, Rakesh J, Aditya A, Sandeep P, Arjun RH, Debasis G: Clear cell chondrosarcoma calcaneum - a case report and review of literature. Foot (Edinburgh, Scotland) 2015, 25:36-40.

7. Stacchiotti S, Baldi GG, Morosi C, Gronchi A, Maestro R: Extraskeletal Myxoid Chondrosarcoma: State of the Art and Current Research on Biology and Clinical Management. Cancers 2020, 12.

8. Mondesir J, Willekens $\mathrm{C}$, Touat M, de Botton S: IDH1 and IDH2 mutations as novel therapeutic targets: current perspectives. Journal of blood medicine 2016, 7:171-80.

9. Chen SS, Tang CH, Chie MJ, Tsai CH, Fong YC, Lu YC et al: Resistin facilitates VEGF-A-dependent angiogenesis by inhibiting miR-16-5p in human chondrosarcoma cells. Cell Death Dis 2019, 10:31.

10. Kim H, Cho Y, Kim HS, Kang D, Cheon D, Kim YJ et al: A system-level approach identifies HIF-2alpha as a critical regulator of chondrosarcoma progression. Nat Commun 2020, 11:5023.

11. Fu P, Shi Y, Chen G, Fan Y, Gu Y, Gao Z: Prognostic Factors in Patients With Osteosarcoma With the Surveillance, Epidemiology, and End Results Database. Technol Cancer Res Treat 2020, 19:1533033820947701.

12. MacDonald IJ, Lin CY, Kuo SJ, Su CM, Tang CH: An update on current and future treatment options for chondrosarcoma. Expert Rev Anticancer Ther 2019, 19:773-86. 
13. Amer KM, Munn M, Congiusta D, Abraham JA, Basu Mallick A: Survival and Prognosis of Chondrosarcoma Subtypes: SEER Database Analysis. J Orthop Res 2020, 38:311-9.

14. Moussalem CK, Massaad E, Baassiri W, Akhtar Anwar M, Kobeissy F, Eid A et al: Spinal sarcomas and immunity: An undervalued relationship. Semin Cancer Biol 2020, 64:36-50.

15. van Praag Veroniek VM, Rueten-Budde AJ, Ho V, Dijkstra PDS, Study group B, Soft tissue t et al: Incidence, outcomes and prognostic factors during 25 years of treatment of chondrosarcomas. Surg Oncol 2018, 27:402-8.

16. Thorkildsen J, Taksdal I, Bjerkehagen B, Haugland HK, Borge Johannesen T, Viset T et al: Chondrosarcoma in Norway 1990-2013; an epidemiological and prognostic observational study of a complete national cohort. Acta Oncol 2019, 58:273-82.

17. Nazeri E, Gouran Savadkoohi M, Majidzadeh AK, Esmaeili R: Chondrosarcoma: An overview of clinical behavior, molecular mechanisms mediated drug resistance and potential therapeutic targets. Crit Rev Oncol Hematol 2018, 131:102-9.

18. Tzeng HE, Tang CH, Wu SH, Chen HT, Fong YC, Lu YC et al: CCN6-mediated MMP-9 activation enhances metastatic potential of human chondrosarcoma. Cell Death Dis 2018, 9:955.

19. Stevenson JD, Laitinen MK, Parry MC, Sumathi V, Grimer RJ, Jeys LM: The role of surgical margins in chondrosarcoma. European journal of surgical oncology : the journal of the European Society of Surgical Oncology and the British Association of Surgical Oncology 2018, 44:1412-8.

20. Song K, Song J, Shi X, Wang H, Ma X, Xia X et al: Development and Validation of Nomograms Predicting Overall and Cancer-Specific Survival of Spinal Chondrosarcoma Patients. Spine (Phila Pa 1976) 2018, 43:E1281-E9.

21. Nie Z, Lu Q, Peng H: Prognostic factors for patients with chondrosarcoma: A survival analysis based on the Surveillance, Epidemiology, and End Results (SEER) database (1973-2012). Journal of bone oncology 2018, 13:55-61.

22. Asfar MM, Hutcheson KA, Won AM: Prosthetic Rehabilitation with Palatal Lift/Augmentation in a Patient with Neurologic/Motor Deficit Due To Cancer Therapy for Chondrosarcoma. Journal of prosthodontics : official journal of the American College of Prosthodontists 2019, 28:234-8.

23. Li JY, Li CJ, Lin LT, Tsui KH: Multi-Omics Analysis Identifying Key Biomarkers in Ovarian Cancer. Cancer Control 2020, 27:1073274820976671.

24. Chen L, Long C, Liu J, Duan X, Xiang Z: Prognostic nomograms to predict overall survival and cancerspecific survival in patients with pelvic chondrosarcoma. Cancer Med 2019, 8:5438-49.

25. Bus MPA, Campanacci DA, Albergo JI, Leithner A, van de Sande MAJ, Gaston CL et al: Conventional Primary Central Chondrosarcoma of the Pelvis: Prognostic Factors and Outcome of Surgical Treatment in 162 Patients. J Bone Joint Surg Am 2018, 100:316-25.

26. Fromm J, Klein A, Baur-Melnyk A, Knosel T, Lindner L, Birkenmaier C et al: Survival and prognostic factors in conventional central chondrosarcoma. BMC Cancer 2018, 18:849.

27. Strotman PK, Reif TJ, Kliethermes SA, Sandhu JK, Nystrom LM: Dedifferentiated chondrosarcoma: A survival analysis of 159 cases from the SEER database (2001-2011). Journal of surgical oncology 
2017, 116:252-7.

28. Amadeo B, Penel N, Coindre JM, Ray-Coquard I, Ligier K, Delafosse $P$ et al: Incidence and time trends of sarcoma (2000-2013): results from the French network of cancer registries (FRANCIM). BMC Cancer 2020, 20:190.

29. Nicolle R, Ayadi M, Gomez-Brouchet A, Armenoult L, Banneau G, Elarouci N et al: Integrated molecular characterization of chondrosarcoma reveals critical determinants of disease progression. Nat Commun 2019, 10:4622.

30. D. Donati A, El Ghoneimy, F. Bertoni, C. Di Bella, M. Mercuri: Surgical treatment and outcome of conventional pelvic chondrosarcoma. The Journal of Bone And Joint Surgery 2005, 87:1527-30.

31. Verdegaal SH, Brouwers HF, van Zwet EW, Hogendoorn PC, Taminiau AH: Low-grade chondrosarcoma of long bones treated with intralesional curettage followed by application of phenol, ethanol, and bone-grafting. J Bone Joint Surg Am 2012, 94:1201-7.

\section{Figures}




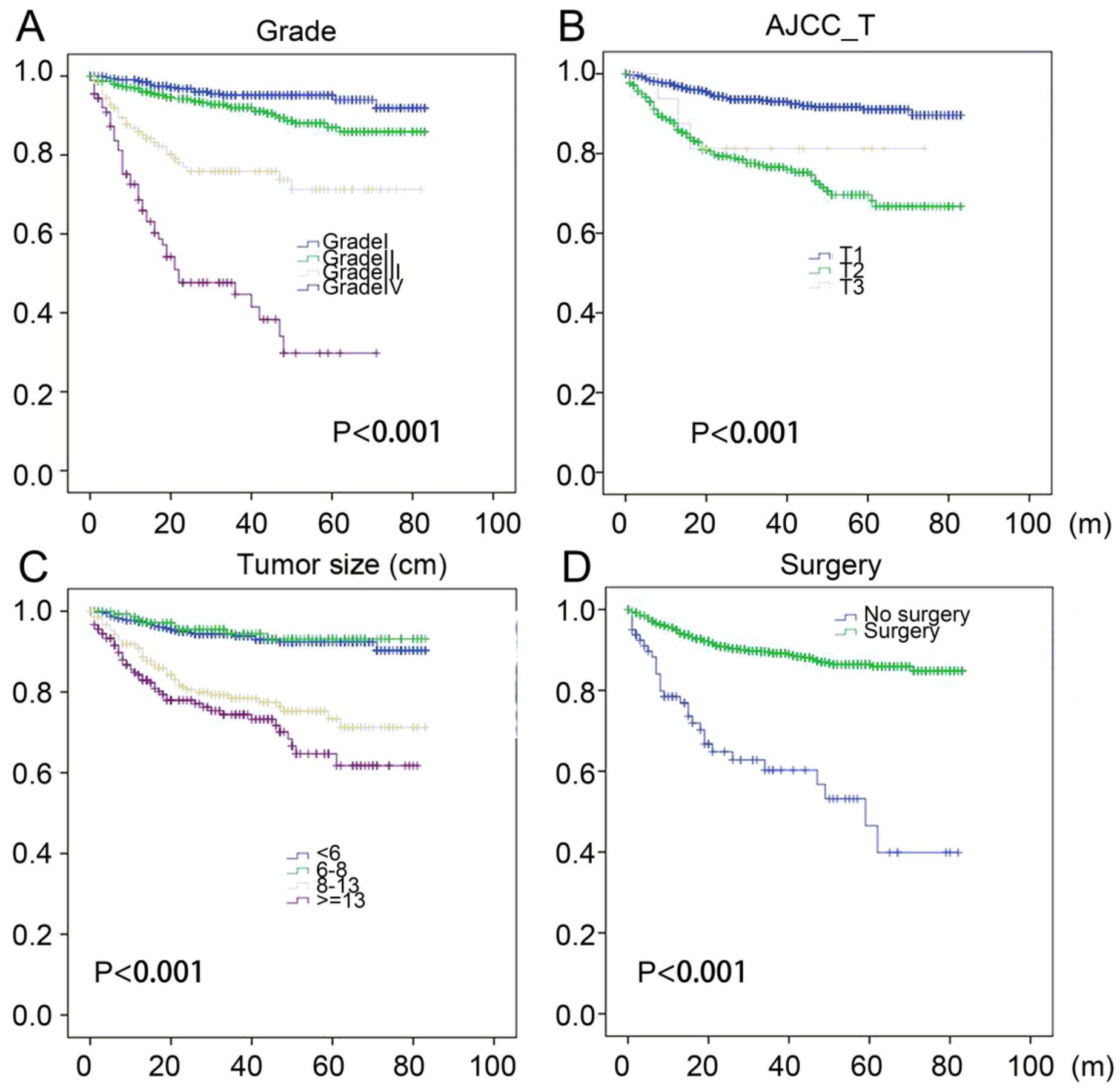

Figure 1

Kaplan-Meier analysis of conventional chondrosarcoma patients including (A) grade, (B) AJCC_T, (C) tumor size, and (D) surgery. 


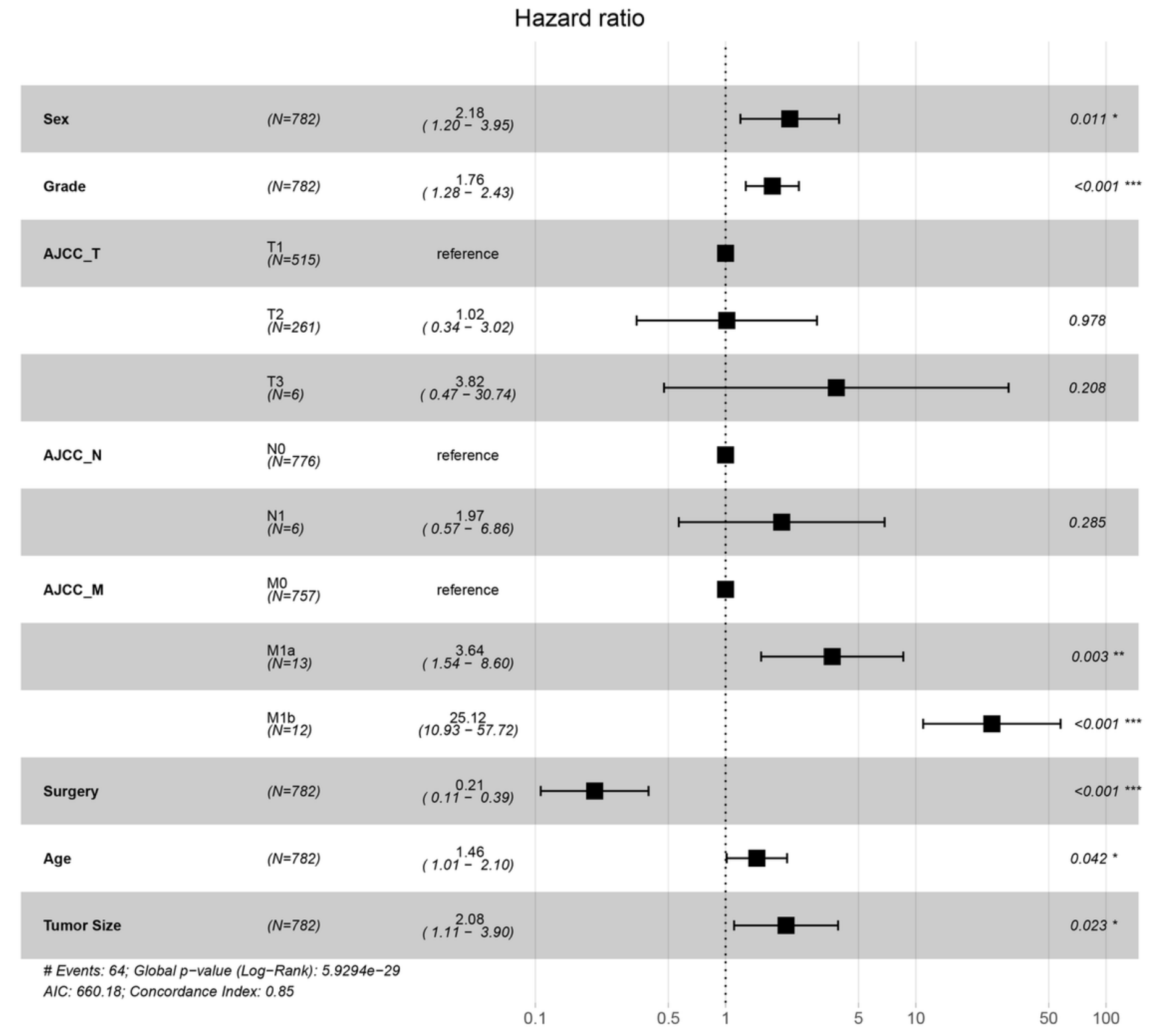

\section{Figure 2}

Multivariable Cox regression analysis of patients with conventional chondrosarcoma visualized with a forest map. 
Points

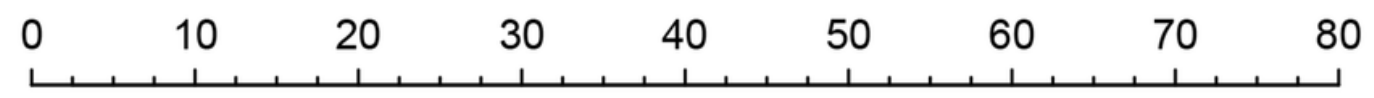

AJCC_M
Surgery
Age
Sex
Grade
Tumor_Size
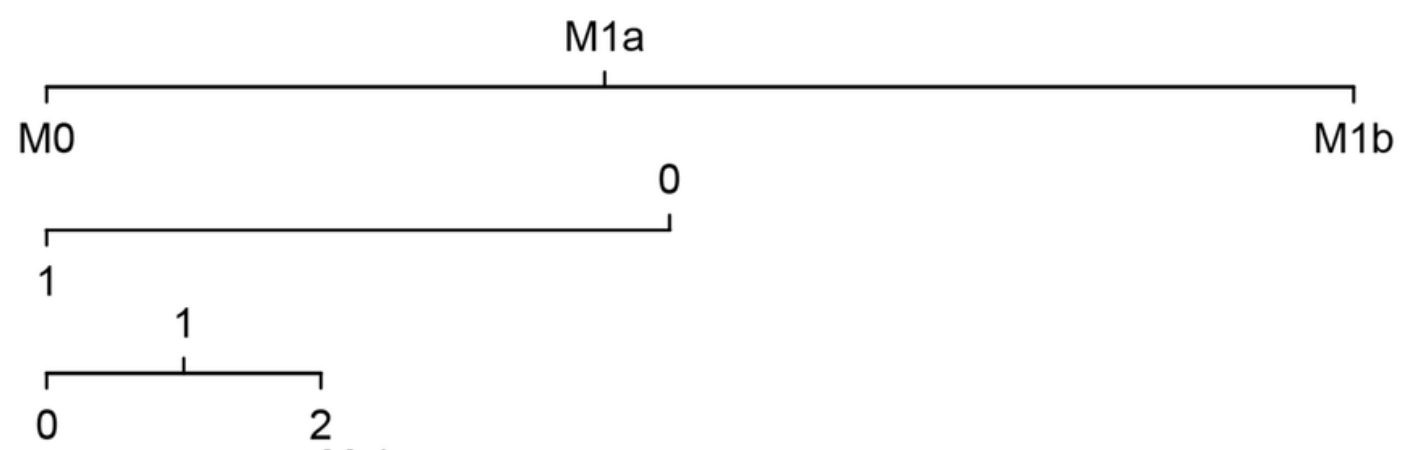

\section{Female}

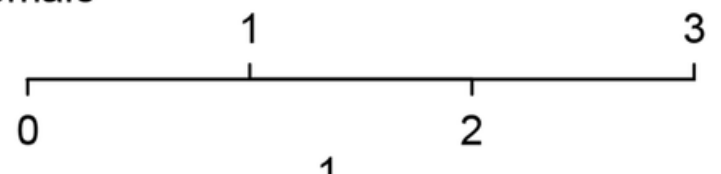

Total Points
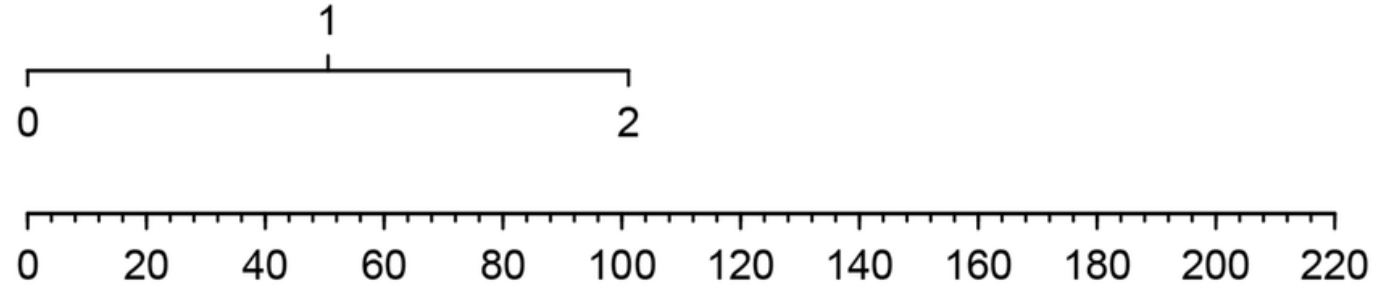

1-year survival

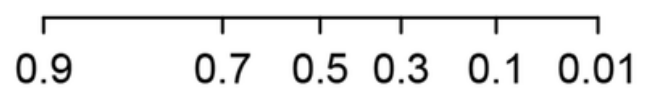

3-year survival

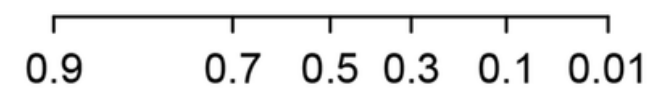

5-year survival

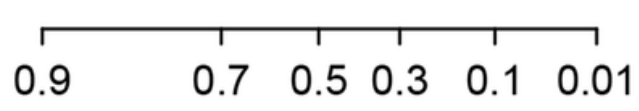

\section{Figure 3}

Nomogram composed of tumor size, AJCC_M, grade, surgery, age and sex. Age: $\leq 45,(0) ;>45, \leq 65,(1)$; $>65$, (2). Grade: well, (0); moderate, (1); poor, (2); undifferentiated, (3). Tumor size: $\leq 8,0 ;>8, \leq 13,1 ;>13,2$. Surgery, 0 ; no surgery, 1. 

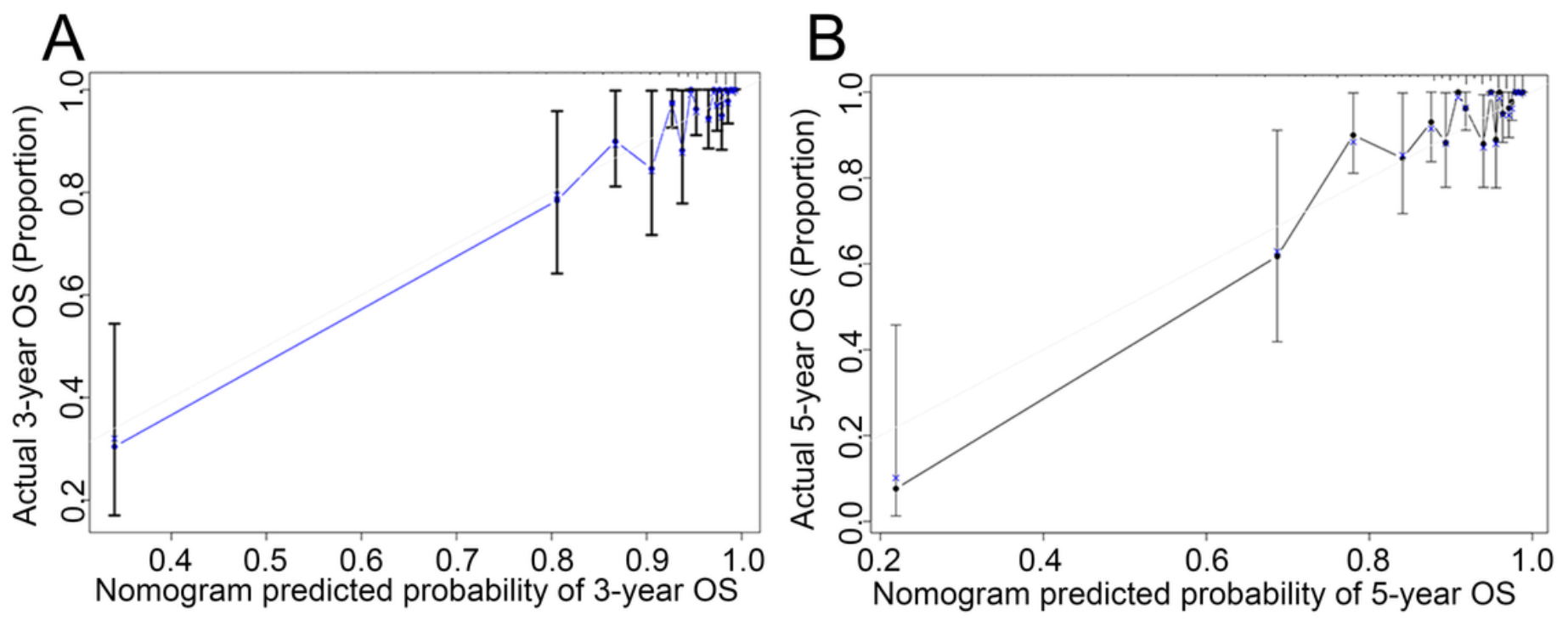

\section{Figure 4}

Internal validation of (A) three-year and (B) five-year overall survival with calibration curves.

A

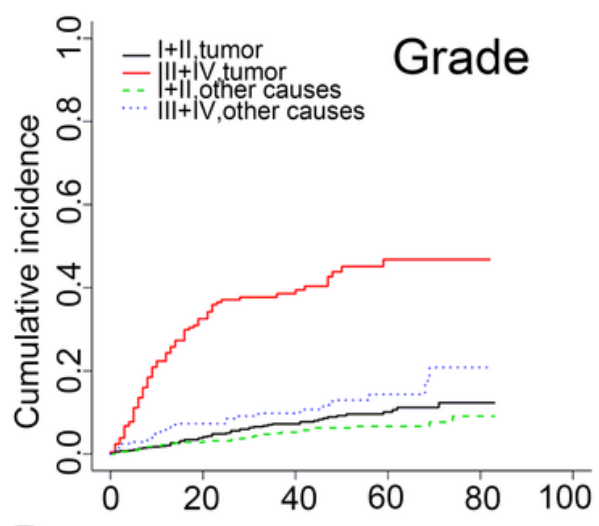

D

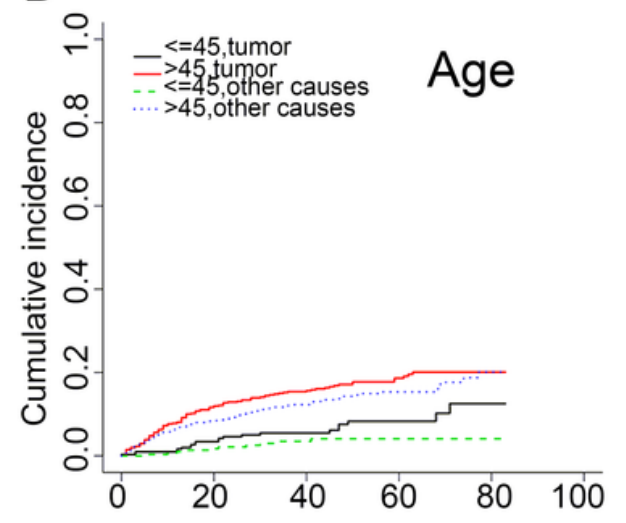

B

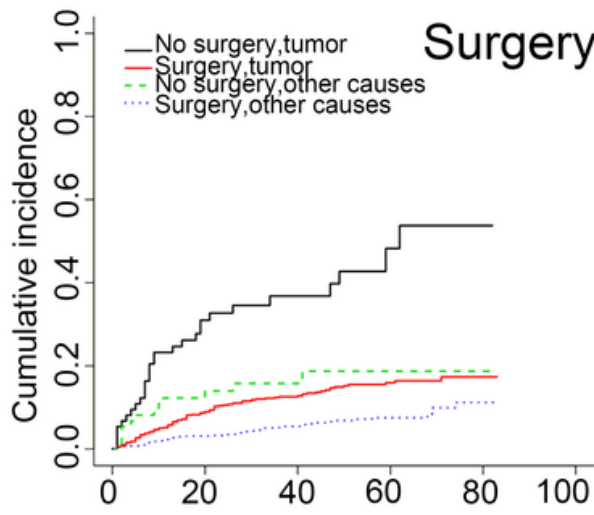

$\mathrm{E}$

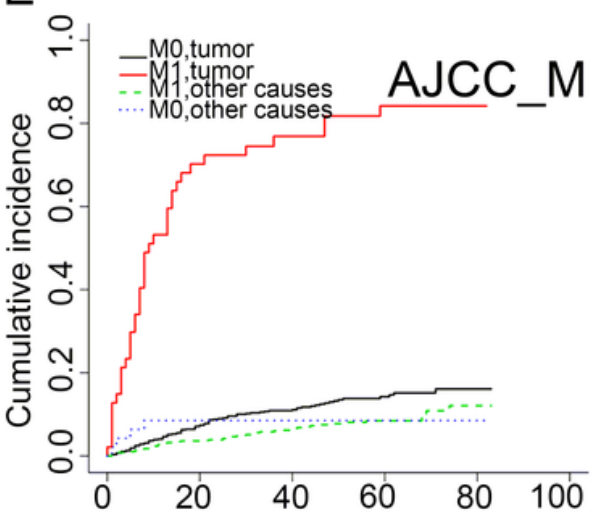

C

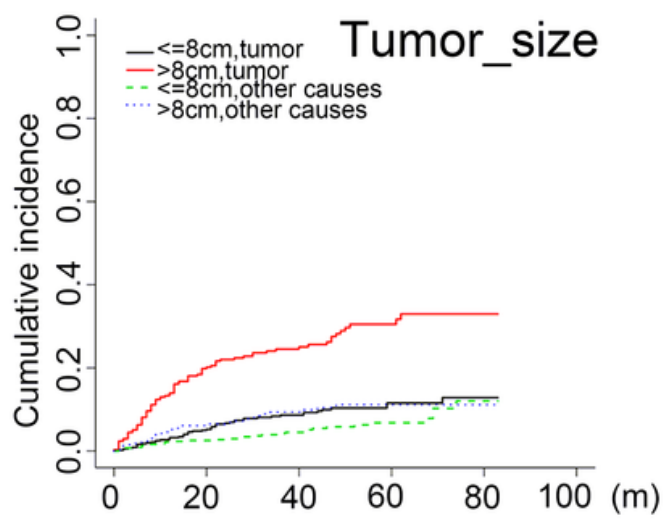

$\mathrm{F}$

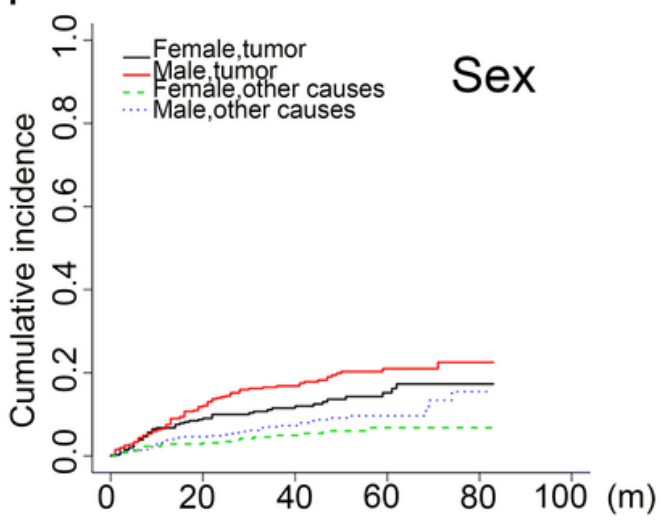

\section{Figure 5}

Competitive factors that may affect chondrosarcoma-specific death with the x-axis representing the survival of months and the $y$-axis representing cumulative incidence. 


\section{Supplementary Files}

This is a list of supplementary files associated with this preprint. Click to download.

- 0609.tif

- Figures2.tif

- Tables1.docx 